\title{
ANÁLISE COMPARATIVA DE PROGRAMAS DE QUALIFICAÇÃO DE FORNECEDORES
}

\author{
SOARES, Daiana Paula Gonçalves ${ }^{1}$ \\ CARRARO, Nilton Cezar ${ }^{2}$ \\ ALBUQUERQUE, Alexandre Faria ${ }^{3}$ \\ YOKOYAMA, Nelson ${ }^{3}$ \\ SOUSA, Marco Aurélio Batista de ${ }^{4}$
}

RESUMO: Perante um mercado cada vez mais exigente e competitivo, atender adequadamente seus clientes vem se tornando um desafio cada vez maior, principalmente quando esses clientes são grandes corporações com presença no mercado internacional, neste trabalho chamadas de âncoras. Para auxiliar o mercado onde estão inseridas, essas empresas investem na qualificação de sua cadeia de suprimentos através de programas de qualificação de fornecedores. Esses programas têm um papel fundamental no desenvolvimento das micro e pequenas empresas, capacitando e certificando, ampliando sua gestão da qualidade. A partir deste fato, este trabalho utilizou-se da metodologia descritiva para analisar a existência de diferenças entre os programas de qualificação de fornecedores. Dentre os programas estudados, apesar de vários pontos em comum, apresentam inúmeras particularidades locais, o que leva a conclusão de que não há um programa de qualificação de fornecedores padronizado entre os pesquisados. Este trabalho não realizou um censo entre todos os programas de qualificação de fornecedores existentes no Brasil.

Palavras-Chave: Certificação. Normatização. Qualidade. Gestão.

SUMMARY: Faced with an increasingly demanding and competitive market, adequately serving its customers has become a growing challenge, especially when these clients are large corporations with presence in the international market, in this work called anchors. To help the market where they are inserted, these companies invest in qualifying their supply chain through supplier qualification programs. These programs play a key role in the development of micro and small enterprises, empowering and certifying, expanding its quality management. From this fact, this work used the descriptive methodology to analyze the existence of differences between the qualification programs of suppliers. Among the programs studied, despite several points in common, have numerous local peculiarities, which leads to the conclusion that there is no standard supplier qualification program among the respondents. This work did not carry out a census among all existing supplier qualification programs in Brazil.

Keywords: Certification. Standardization. Quality. Management.

RESUMEN: Ante un mercado cada vez más exigente y competitivo, atender adecuadamente a sus clientes se está convirtiendo en un desafío cada vez mayor, principalmente cuando estos clientes son grandes corporaciones con presencia en el mercado internacional, en este trabajo llamadas de anclas. Para ayudar al mercado donde están insertas, las empresas invierte en la calificación de su cadena de suministros a través de programas de calificación de proveedores. Estos programas desempeñan un papel fundamental en el desarrollo de las micro y pequeñas empresas, capacitando y certificando, ampliando su gestión de la calidad. A partir de este hecho, este trabajo se utilizó de la metodología descriptiva para analizar la existencia de diferencias entre los programas de calificación de proveedores. Entre los programas estudiados, a pesar de varios puntos en común, presentan innumerables particularidades locales, lo que lleva a la conclusión de que no hay un programa de calificación de proveedores estandarizado entre los encuestados. Este trabajo no realizó un censo entre todos los programas de calificación de proveedores existentes en Brasil.

\footnotetext{
${ }^{1}$ UFMS - Universidade Federal de Mato Grosso do Sul - Bacharel em Administração

${ }^{2}$ UFMS - Universidade Federal de Mato Grosso do Sul. Professor Adjunto - Doutor em Engenharia de Produção. Mestre em Contabilidade

${ }^{3}$ UFMS - Universidade Federal de Mato Grosso do Sul - Professor Adjunto no Curso de Administração

${ }^{4}$ UFMS - Universidade Federal de Mato Grosso do Sul - Professor Adjunto no Curso de Ciências Contábeis
} 
Palabras-Clave: Certificación. Normatización. Calidad. Gestión.

\section{INTRODUÇÃO}

A qualificação de fornecedores tem sido cada vez mais procurada por diversos setores da economia e vem sendo muito difundida principalmente no desenvolvimento das micro e pequenas empresas, visando o desenvolvimento dos elos da cadeia produtiva de grandes indústrias com o intuito de melhorar quantitativa e qualitativamente a participação de fornecedores nesta cadeia.

Essa condição deu origem a programas de qualificação de fornecedores denominados Programa Integrado de Desenvolvimento e Qualificação de Fornecedores (PRODFOR), Qualidade, Logística, Inovação, Custo/Contrato, Atendimento e Relacionamento (QLICAR), Programa de Qualificação de Fornecedores (PQF) e Programa de Desenvolvimento de Fornecedores da Gerdau (PDF).

O surgimento do primeiro programa de qualificação no Brasil se deu no Espírito Santo, em 1997, com o PRODFOR. Atualmente, o programa abrange 17 estados do Brasil, com Pernambuco e Santa Catarina desde 2007 e Mato Grosso do Sul desde 2008, em ambos o programa recebe a denominação PQF. Esse tipo de programa também foi desenvolvido diretamente por empresas compradoras como a Natura desde 2005, com o denominado QLICAR e pela Gerdau Rio-grandense desde 2006, com o denominado PDF.

No estado do Espirito Santo o PRODFOR foi criado com uma metodologia voltada a gestão da qualidade através da norma Sistema de Gestão da Qualidade de Fornecimento (SGQF), que tem como base todos os requisitos da ISO 9001 - norma internacional que certifica a gestão da qualidade da empresa - e mais um requisito de Saúde e Segurança de Trabalho (SST) e outro requisito de Meio Ambiente (MA). O mesmo fundamento é utilizado pelo Programa de Qualificação de Fornecedores (PQF) no estado de Mato Grosso do Sul.

O objetivo deste trabalho é fazer uma análise comparativa de alguns programas de qualificação de fornecedores buscando responder a seguinte questão: Existem diferenças entre os programas de qualificação de fornecedores? Quais? Justifica-se este questionamento em função da inferência que existem diferenças na metodologia utilizada entre os programas de qualificação de fornecedores e consequentemente nos resultados alcançados.

Para tanto, além desta breve introdução contextualizando passado e presente sobre o assunto programas de qualificação de fornecedores, também serão apresentados na próxima seção recortes sobre os pilares teóricos desses programas que fundamentaram as análises comparativas e as considerações finais que serão apresentadas nas seções 4 e 5 .

\section{FUNDAMENTAÇÃO TEÓRICA}

Em um ambiente altamente competitivo, surge a importância do bom relacionamento entre empresas e fornecedores. Deming (1990) reafirmou a necessidade de se estabelecer um relacionamento próximo com fornecedores, e definiu quatorze princípios de gestão da qualidade. Entre eles, o quarto princípio destaca essa importância ao afirmar que se deve abandonar a prática de aprovação de orçamentos unicamente com base no valor, levando em consideração o desenvolvimento do fornecedor, possibilitando assim um relacionamento de longo prazo, baseado na fidelidade e confiança.

Já Krause e Ellram (1997) definem desenvolvimento de fornecedores como qualquer tentativa ou 
esforço de uma empresa compradora em relação a seus fornecedores para melhorar seu desempenho e/ou possibilidade e suprir as necessidades de suprimentos de curto e longo prazo da empresa compradora.

Segundo Maia e Cerra (2004) a confiança mutua é um dos requisitos primordiais da parceria e está condicionada ás relações de longo prazo. Mchug et al. (2003) reforçam esses posicionamentos ao afirmarem que as relações de parcerias são identificadas por relacionamentos de longo prazo baseado mais na confiança do que na competição.

Para que as condições levantadas anteriormente sejam estabelecidas são necessárias observar requisitos mínimos que serão detalhados nas próximas seções com o objetivo de fundamentar as discussões e o posicionamento adotado neste trabalho.

\subsection{Programas de Qualificação de Fornecedores}

Os programas de qualificação de fornecedores podem ser elaborados sob dois enfoques: de modo limitado, envolvendo a produção de novas fontes de fornecimento, quando não existem fornecedores adequados para os requisitos da empresa. De forma mais ampla, envolvendo atividades que visam a melhoria de fornecedores com os quais a empresa já tem uma relação, ou seja, a melhoria das habilidades existentes no fornecedor para atender os requisitos de mudança competitiva (HAHN et al., 1990).

Para Kotler (2000), os compradores de bens e serviços das empresas realizam suas funções com o objetivo de diminuir custos operacionais ou atender obrigações legais ou sociais, identificando três tipos de compras corporativas:

a) compras propriamente ditas: são operações simples com os fornecedores, no qual em grande parte o relacionamento entre compradores e vendedores é distante e por vezes conflituosa;

b) seleção de fornecedores: existe uma aproximação com um pequeno grupo de fornecedores, buscando, ao mesmo tempo, aumento da qualidade e diminuição de custos, gestão de compras, as transformações e os custos de vendas. Nesse modo trabalham de maneira muito próxima, e o;

c) gerenciamento de suprimentos: que visa reconhecer o papel da compra como uma intervenção de incorporar valor, onde a empresa busca aperfeiçoar toda a cadeia produtiva, desde a matéria prima até o consumidor final.

Segundo Moura (2009) um fornecedor qualificado é aquele que apresenta uma organização que atende aos requisitos esperados, sendo avaliados através de auditoria ou outra maneira de mostrar ter a capacidade de atender na quantidade, qualidade e/ou no prazo determinado pela empresa cliente.

De acordo com Ferreira (2005) quando há um Sistema de Gestão da Qualidade implementado e baseado em uma norma internacional, os clientes se tornam mais seguros com o fornecedor e sua capacidade de seguir aos requisitos estabelecidos, garantindo a qualidade dos seus produtos ou serviços.

Para Ching (1999), a implementação de um sistema de qualidade baseado no Lean Manufacturing oferece algumas vantagens, como parceiros mais fortes, foco comum na qualidade, credibilidade de entregas mais estáveis e repetitivas, níveis de estoque mais baixos, diminuição da burocracia, aumento do controle de processo, dependência mútua e congruência de objetivos e diminuição no custo da cadeia logística.

Segundo Vieira (2014) a parceria entre grandes empresas compradoras na aplicação de um programa de desenvolvimento e qualificação de fornecedores viabiliza a diminuição de esforços e custos envolvidos. O efeito disso é a possibilidade dessas empresas atingirem novos mercados e a capacidade de melhores produtos e serviços para os consumidores em geral. 
Para garantir que as empresas atendam aos requisitos estabelecidos, é necessário apoiarem-se em normas que regularizem todo o processo, denominadas de princípios da normatização nos casos estudados.

A norma utilizada com maior frequência é a International Organization for Standardization (ISO) 9001. Seguida da ISO 14001 e Occupational Health and Safety Assessment Services (OHSAS) 18001, que são utilizadas na integra ou parcialmente (alguns requisitos ou a ideia da norma de forma resumida).

\subsection{Princípios da normatização}

Cada PQF tem um cronograma e um sistema de implementação, embora todos tenham algum embasamento em normas para a avaliação de fornecedores. O PRODFOR tem duração de 12 meses e os PQFs variam entre 12 e 18 meses para realização de todo o ciclo. Isso porque alguns programas utilizam a metodologia básica que não faz a implementação de nenhuma normatização específica, onde seu papel fundamental é o ajuste de obrigações de legalidade constitucional, fiscal, financeira e gestão sustentável (REVISTA PQF, 2015).

A ISO 9001 é uma norma que define requisitos na área da gestão empresarial. São apresentadas exigências na administração com o objetivo de gerenciar os requisitos do cliente para que o entendimento e o atendimento desses requisitos sejam eficazes. O objetivo maior da norma é fazer com que as organizações atendam aos requisitos exigidos pelo cliente. Os oito princípios da norma ISO 9001:2008 são: o foco no cliente, liderança entre objetivos comuns, envolvimento de todos, abordagem de processos, o impacto de decisões em outros processos, melhoria continua, decisão baseada em dados e benefícios mútuos entre clientes e fornecedores (MOURA, 2009).

A ISO 9001:2008 é uma norma que define os requisitos de um Sistema de Gestão da Qualidade, que tem por objetivo a melhoria contínua da empresa, através do planejamento, do controle e das ações corretivas e preventivas, estruturada de acordo com o Ciclo Plan-Do-Check-Adjust (PDCA). A norma 9001:2008 está agrupada da seguinte maneira: introdução, escopo, referência normativa, termos e definições, sistema de gestão da qualidade, responsabilidade da direção, gestão de recursos, realização do produto, medição, análise e melhoria. Dessa norma é que se baseia o Sistema de Gestão da Qualidade de Fornecimento (SGQF), (MOURA, 2009).

A Associação Brasileira de Normas Técnicas (ABNT NBR) por meio da ISO 14001 é outra norma citada ou tratada na integra dos requisitos de um Sistema de Gestão Ambiental (SGA) e permite que a empresa desenvolva políticas ambientalmente sustentáveis, levando em conta os aspectos ambientais influenciados pela organização e outros passíveis de serem controlados por ela. A ISO 14001 trata de um sistema de gestão ambiental, cujos principais objetivos são respeitar o direito ambiental, controlar os riscos para a área, controlar os custos dos dejetos, tornar-se competitivo em relação à concorrência e a valorização da imagem da empresa. Por sua vez a ISO 14000 serviu de base para a criação do SGA que incluiu a redução e riscos de acidentes, economia ou redução do consumo de matérias primas, água e energia, melhoria nos processos entre outros (REVISTA PQF, 2015).

Já no Sistema de Gestão de Saúde e Segurança Ocupacional (SGSS), a norma utilizada como espelho é a OHSAS 18000 que determina toda a sustentação dos objetivos e abrangências sobre temas que se estendem desde o controle e monitoramento dos procedimentos até o levantamento de perigos e riscos. As vantagens desses programas se reforçará nos próximas sessões.

\subsection{Metodologias aplicadas na Qualificação de Fornecedores}

A metodologia do Prodfor e dos PQFs é similar, pois o Prodfor serviu como referência para os 
PQFs. Segundo o Portal da Indústria (2016), o PQF é composto, por quatro etapas: sensibilização, diagnóstico, qualificação e certificação. A sensibilização é a primeira etapa do processo de implantação do PQF, que tem como metas a mobilização e a adesão de empresas-âncoras, empresas fornecedoras e parceiros. Além disso, é constituído um Comitê Gestor Local, que é o responsável pela condução do programa na região.

Uma vez concluída a sensibilização, a etapa seguinte é a análise das empresas a serem qualificadas, a partir de requisitos definidos pelas empresas-âncora. A base metodológica desta etapa do programa é o benchmarking industrial, que é aplicado em todas as empresas fornecedoras participantes. Isso permite a identificação de oportunidades de ações coletivas, baseadas nos pontos fracos e fortes comuns aos avaliados. Além disso, ao final do processo, é traçado o perfil completo e individual, contendo pontos fortes e fracos das empresas. Os relatórios são chamados de diagnósticos e apontam os requisitos de qualificação que orientarão a próxima etapa do PQF (PORTAL DA INDÚSTRIA, 2016; PEREIRA et al., 2016).

Para Moura (2009) a terceira etapa é a qualificação, que ocorre em duas partes:

- Seminários técnicos coletivos, que abordam conceitos básicos da norma realizados na forma de cursos de capacitação dividido em módulos de estudo com carga horário de 8 horas;

- Consultorias individuais, para a orientação e verificação do desenvolvimento das atividades de implementação em cada etapa da norma, além de auxiliar as empresas em dificuldades comuns e preparar para a última etapa a auditoria.

Segundo Moura (2009) ao fim da etapa de certificação das empresas fornecedoras a qualificação da mesma é verificada por meio de auditorias. Os auditores são das próprias âncoras e profissionais da área que devem ter formação e experiência comprovada, é avaliado o atendimento dos requisitos estabelecidos pelo Sistema de Gestão da Qualidade de Fornecimento - SGQF no caso dos PQFs e do PRODFOR. A empresa fornecedora que obtiver aprovação nesse processo receberá um Certificado de Fornecedor Qualificado.

Pereira et al. (2016) descreve que o Certificado de Fornecedor Qualificado é entregue na etapa que fecha o ciclo, denominada Certificação onde ocorre um evento solene. Estes certificados possuem validade de dois anos, onde após esse prazo, faz-se necessária auditorias anuais de comprovação de continuidade de gestão da qualidade.

A Revista PQF (2015) afirma que a implementação de procedimento possibilita capacidade de demonstração do sistema funcional e organizacional da empresa. As atividades estabelecidas visam demonstrar uma continuação coerente em suas atividades.

Segundo Silveira (2007) o PDF da Gerdau é desenvolvido em cinco etapas, com duração de 18 meses, o que possibilita que o modelo adotado atinja os objetivos ao longo de um determinado tempo e desta forma seus resultados possam ser apresentados e monitorados conforme a Figura 1. 
Figura 1: Desempenho das etapas operacionais do projeto

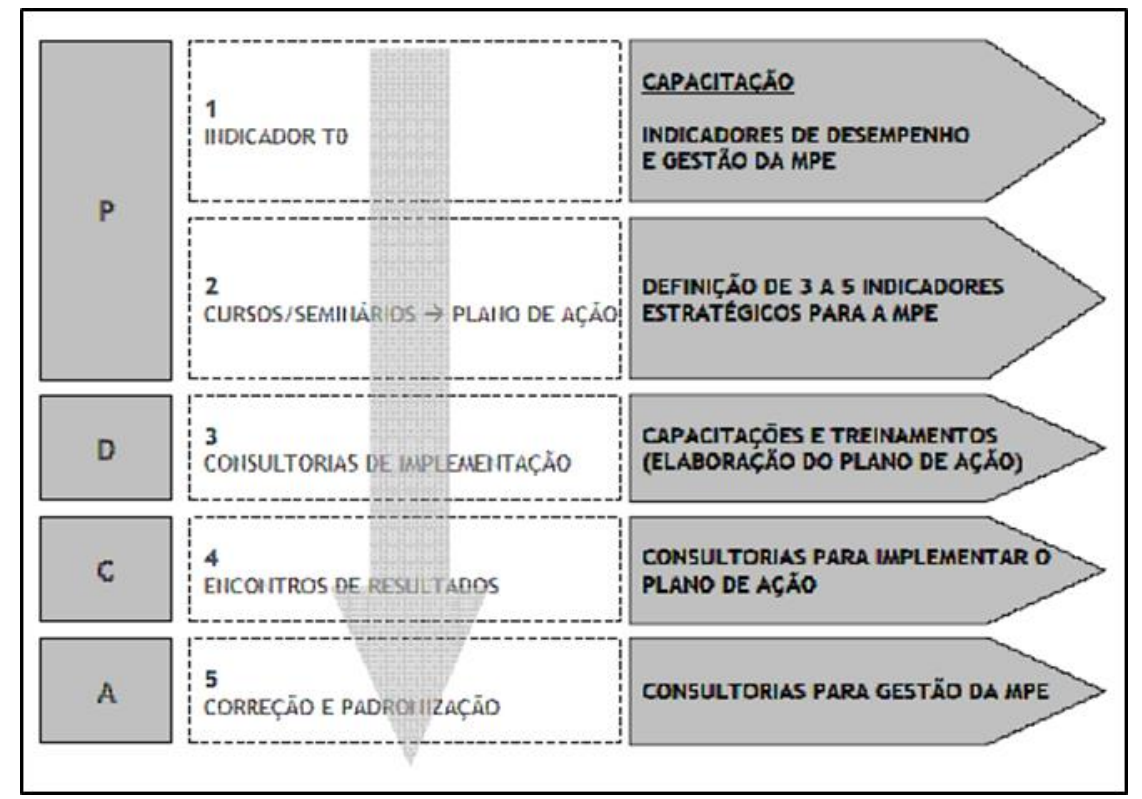

Fonte: Silveira (2007)

Para a Natura (2016) o QLICAR tem o objetivo de incentivar o funcionamento da cadeia de suprimentos por meio do gerenciamento do desempenho dos fornecedores e de ações crescimento conjunto de processos. O principal objetivo do programa é a melhoria continua dos seus fornecedores baseada em seis pilares, significando qualidade; logística; inovação; custo/contrato; atendimento e relacionamento.

A supervisão e avaliação do processo ficam sob responsabilidade da Natura e é desenvolvido por um sistema de pontuação chamado "Painel QLICAR". Com o intuito de apontar e reconhecer os fornecedores com melhores aplicações dentro dos indicadores pré-estabelecidos por categorias. As categorias são manufatura de insumos; manufatura de produtos acabados; brindes, acessórios e materiais de apoio; transportes; operadores logísticos e atendimento.

De acordo com Sediyama (2012) o fornecedor passa por quatro etapas dentro do programa para completar o ciclo de desenvolvimento:

- Avaliação do candidato a fornecedor: onde inicialmente a empresa candidata deve enviar cópia de suas documentações para análise, juntamente com alguns questionários ambientais e sociais respondidos. Toda essa documentação tem o prazo de 15 dias para ser analisada pela Natura e aprovar ou não a empresa como parte da base de fornecedores.

- Aprovação de Cadastro: concluído o cadastramento a empresa entra no sistema da Natura e é submetida a uma verificação de condições. Itens como logística, política comercial e desenvolvimento do plano de ação, é a base para busca de indicadores de monitoramento de melhoria contínua.

- Qualificação: nesse ponto a empresa passa a ser verificada por indicadores do QLICAR. As avaliações ocorrem mensalmente através do "Scorecard de Fornecedores". Esse por sua vez é um sistema de pontuação utilizado para identificar e apontar as melhores práticas a partir de indicadores préestabelecidos.

- Certificação: o fornecedor que atingir 75\% dos pontos verificados no período é certificado e a validade do certificado é de um ano, prazo para a realização de um novo ciclo do programa. Caso um fornecedor não atinja a pontuação necessária para certificação no ano seguinte ele perde a 
condição de fornecedor certificado.

Uma vez realizada toda esta base de fundamentação teórica para execução do objetivo determinado para este trabalho, foi necessário estabelecer uma base metodológica, conforme descrição na próxima seção.

\section{ASPECTOS METODOLÓGICOS}

O presente trabalho é de natureza descritiva, com abordagem do problema de pesquisa caracterizado como qualitativo. Raupp e Beuren (2009, p. 92) defendem que essa abordagem conduz "análises mais profundas em relação ao fenômeno estudado". Com relação à coleta de dados, baseou-se no método bibliográfico e documental. A necessidade da utilização dos dois métodos como ressalta Fonseca (2002), dá-se porque a pesquisa bibliográfica utiliza de fontes já elaboradas como livros e artigos científicos, enquanto que a pesquisa documental utiliza de fontes diversas sem tratamento analítico como revistas, relatórios, documentos oficiais e informações provenientes da internet.

Após conhecer o PQF/MS onde foi possível observar a mudança que ocorre na gestão das empresas que passam pelo programa, surgiu à dúvida de como ações voltadas a gestão da qualidade e apoio à micro e pequenas empresas vêm se desenvolvendo ao longo do território nacional nos últimos anos.

Com o objetivo de levantar as melhores práticas para analisa-las e verificar as diferenças entre elas, observando assim os pontos fortes de cada técnica encontrada e buscar pontos em comum entre elas para que se possa fazer um comparativo e estabelecer se possível qual programa se destaca entre os demais, foram utilizados dados abertos e informações obtidas através de e-mails para a realização da coleta de dados que foram utilizados ao longo desse trabalho.

O cruzamento de dados para análise será evidenciado por meio de tabelas apresentadas na seção 4, juntamente com uma comparação entre o conteúdo normativo apresentado em cada programa.

\section{APRESENTAÇÃO E ANÁLISE DOS DADOS}

Os programas de qualificação de fornecedores possuem empresas mantenedoras que são chamadas de âncoras. Estas são as principais entusiastas do mesmo e sua função dentro dele é coordenar a execução do programa estabelecendo seus parâmetros de alcance e exigências, são elas também que subsidiam o custo do programa parcialmente ou em sua totalidade para possibilitar assim principalmente a participação de micro e pequenas empresas, que são normalmente as maiores beneficiadas por não ser possível custear a totalidade do valor de participação de um processo de capacitação desse nível individualmente.

O Prodfor conta com as seguintes âncoras: Arcelor Mittal, Canexus, Cesan, EDP Escelsa, Fibria, Petrobras, Samarco, Vale e Technip, além do apoio do Serviço Brasileiro de Apoio às Micro e Pequenas Empresas (SEBRAE) e da Federação das Indústrias do Espírito Santo (FIES) através de sua casa de apoio a empresa Instituto Euvaldo Lodi (IEL/ES). Enquanto o PQF/MS conta com Fibria, Sitrel e Bemis Latin America e da Prefeitura Municipal de Três Lagoas como âncoras, recebendo o apoio da FIEMS através do IEL/MS e do SEBRAE. Já o PQF/SC conta com as provedoras Altona, Wetzel e MR Riosulense, com o apoio do SEBRAE e FIESC, através do IEL/SC. Em Pernambuco o PQF possuiu como âncora a Fiat Chrysler Automobiles (FCA), com o apoio da FIEPE através do IEL/PE. O QLICAR é mantido pela Natura e o PDF pela Gerdau Rio-grandense. Tais investimentos são realizados pelas âncoras com intuito de atender suas próprias certificações e também buscam desenvolver o mercado onde estão inseridas. 
Para a obtenção dos certificados das normas, no entanto, a empresa deve passar por um processo continuo de aprendizado e comprovar o cumprimento dos requisitos exigidos através da forma de avaliação determinada. A Tabela 1 apresenta as principais diferenças entre os PQFs.

Tabela 1: Programas de Qualificação de Fornecedores em números

\begin{tabular}{c|c|c|c|c|c|c}
\hline \multicolumn{2}{l|}{} & $\begin{array}{c}\mathbf{N}^{\mathbf{0}} \text { de } \\
\text { Âncoras }\end{array}$ & $\begin{array}{c}\mathbf{N}^{\mathbf{0}} \text { de Empresas } \\
\text { Certificadas }\end{array}$ & $\begin{array}{c}\text { Anos de } \\
\text { Início }\end{array}$ & $\begin{array}{c}\text { Validade do } \\
\text { Certificado } \\
\text { (anos) }\end{array}$ & $\begin{array}{c}\text { Situação no } \\
\text { ano de 2016 }\end{array}$ \\
\hline 1 & PRODFOR & 9 & 646 & 1997 & 2 & Ativo \\
\hline 2 & PQF/SC & 26 & 400 & 2007 & Não há & Ativo \\
\hline 3 & PQF/PE & 1 & 31 & 2014 & Não há & Inativo \\
\hline 4 & PQF/MS & 4 & 127 & 2008 & 2 & Ativo \\
\hline 5 & QLICAR & 1 & 100 & 2004 & 1 & Ativo \\
\hline 6 & PDF & 1 & 404 & 2007 & $\begin{array}{c}\text { Não } \\
\text { Informado }\end{array}$ & Ativo \\
\hline
\end{tabular}

Fonte: Adaptado de Trindade (2016); Iel-pe (2017); Santos (2017); Bittar (2017); Sediyama (2012); Silveira (2007); Gerdau (2017); Bosi (2017).

No Quadro 1 são apresentadas as normas que cada programa segue. Essas normas são utilizadas diferentemente em cada programa com o intuito de nivelamento em sua gestão e atendimento as exigências normativas de fornecimento das âncoras.

Quadro 1: Comparativo entre Programas de Qualificação de Fornecedores Estudados

\begin{tabular}{|c|c|c|c|c|c|c|c|}
\hline $\begin{array}{l}\text { Pré-requisitos teóricos para } \\
\text { Qualificação de Fornecedores }\end{array}$ & $\begin{array}{l}\text { Fonte } \\
\text { teórica }\end{array}$ & PRODFOR & $\mathrm{PQF} / \mathrm{SC}$ & PQF/PE & PQF/MS & QLICAR & PDF \\
\hline Atende algum SGQ & $\begin{array}{l}\text { Ferreira } \\
(2005)\end{array}$ & $\mathbf{S}$ & $\mathbf{S}$ & $\mathbf{S}$ & $\mathbf{S}$ & $\mathbf{N}$ & $\mathbf{S}$ \\
\hline Oferta a ISO 14001 ou SGA & Secão 2.2 & $\mathrm{~S}$ & $\mathrm{~N}$ & $\mathrm{~N}$ & $\mathrm{~N}$ & $\mathrm{~N}$ & $\mathrm{~S}$ \\
\hline Oferta a ISO 9001 ou SGQF & Seção 2.2 & $\mathrm{~S}$ & $\mathrm{~N}$ & $\mathrm{~N}$ & $\mathrm{~N}$ & $\mathrm{~N}$ & $\mathrm{~N}$ \\
\hline $\begin{array}{l}\text { Oferta a OHSAS } 18001 \text { ou } \\
\text { SGSS }\end{array}$ & Seção 2.2 & $S$ & $\mathrm{~N}$ & $\mathrm{~N}$ & $\mathrm{~N}$ & $\mathrm{~N}$ & $\mathrm{~N}$ \\
\hline Oferta outra metodologia? & Seção 2.2 & $\mathrm{~S}$ & $\mathrm{~S}$ & $\mathrm{~S}$ & $\mathrm{~S}$ & $\mathrm{~S}$ & $\mathrm{~N}$ \\
\hline Treinamentos & $\begin{array}{l}\text { Moura } \\
(2009)\end{array}$ & $\mathrm{S}$ & $\mathrm{S}$ & $\mathrm{S}$ & $\mathrm{S}$ & $S$ & $\mathrm{~S}$ \\
\hline Consultorias & $\begin{array}{l}\text { Moura } \\
(2009)\end{array}$ & $S$ & $S$ & $\mathrm{~N}$ & $S$ & $S$ & $S$ \\
\hline Auditorias & $\begin{array}{l}\text { Moura } \\
(2009)\end{array}$ & $S$ & $\mathrm{~N}$ & $S$ & $\mathrm{~N}$ & $\mathrm{~N}$ & $S$ \\
\hline Certificação & $\begin{array}{l}\text { Pereira et al } \\
\quad(2016)\end{array}$ & $S$ & $S$ & $S$ & $S$ & $S$ & $S$ \\
\hline
\end{tabular}

Fonte: Elaborado pelos Autores

O Lean Manufacturing é utilizado como base no PQF em Santa Catarina. Em Pernambuco a metodologia utilizada foi adequada a FCA - utilizando critérios de fornecimento; Lean Manufaturing; gestão da qualidade; gestão ambiental, sistema de gestão fiscal, financeira e trabalhista; saúde e segurança no trabalho ainda há capacitação para as áreas financeira, fiscal e trabalhista.

A norma SGQF utilizada no PQF/MS e Prodfor, essa por sua vez contempla todos os requisitos da ISO 9001:2008 e mais um requisito de meio ambiente e outro de saúde e segurança no trabalho. Em alguns dos 17 estados onde o PQF está presente no Brasil ainda há a metodologia conhecida como PQF 
Básico, o objetivo desse método é a regularização, adequação de gestão, requisitos de legalidade constitucional, fiscal e financeira que visam tornar a empresa sustentável.

O PDF não possui norma específica apenas um apoio ao micro e pequeno empresário através de qualificações e o QLICAR da Natura qualifica a partir do monitoramento amostral de seus fornecedores e

premia as boas práticas e as empresas que são destaques, porém diferentemente dos demais programas o QLICAR não tem um foco voltado para MPE, ele busca desenvolver e fortificar relações com seus fornecedores não fazendo distinção do tamanho do mesmo.

\section{CONSIDERAÇÕES FINAIS}

O objetivo desse trabalho foi realizar uma análise comparativa de alguns programas de qualificação de fornecedores buscando responder se existem e quais são diferenças entre os programas de qualificação de fornecedores analisados.

Uma constatação obtida durante a realização da pesquisa bibliográfica e de campo, foi que para o atendimento de exigências internacionais, onde as empresas que negociam suas mercadorias no mercado externo necessitam adquirir seus insumos de empresas com sua gestão consolidada e voltada para a qualidade, satisfação do cliente, minimização dos impactos ambientais e redução dos riscos de acidentes, afastamentos e ações trabalhistas. Há ainda o compromisso implícito de desenvolvimento regional muito forte nas empresas de grande porte, que buscam possibilitar melhorias ao seu redor, a partir desse princípio essas são parceiras na capacitação das micro e pequenas empresas, e normalmente aderem ou desenvolvem programas próprios para tal.

Foi observado também que dentre os diversos tipos de programas, muitos se assemelham no nome, outros pela metodologia, mas se diferenciam na abordagem utilizada devido a diferenças de necessidades regionais, e realidade da gestão das empresas atendidas. Além de proporcionar enfoques distintos voltados para as necessidades das âncoras que são grandes entusiastas dos programas.

O objetivo de todos os programas estudados é de que ao final do processo as empresas participantes dos programas sejam capazes de crescer de maneira sustentável, manter sua gestão consolidada, buscando uma melhoria contínua através dos ensinamentos adquiridos durante o processo de capacitação. Possibilitando assim que as empresas que passam por esses tipos de programas tornem-se mais competitivas devido a uma maior eficiência foco em sua gestão.

Não foi encontrado na literatura um modelo ideal de programa de desenvolvimento de fornecedores, mas ao seguir as normas contidas em programas de qualificação, a empresa cria uma vantagem competitiva em relação aos concorrentes, pois, a certificação demonstra o quanto à empresa se preocupa em se adequar aos requisitos impostos pelos clientes. Também ganham com a eficiência no fornecimento, a redução dos custos com transporte e dos riscos da cadeia de suprimentos. Como os fornecedores são monitorados permanentemente no cumprimento dos requisitos legais, a âncora fortalece sua imagem de empresa social e ambientalmente responsável.

A principal dificuldade dessa pesquisa foi à dimensão geográfica brasileira, além da variação cultural e econômica, que faz com que cada um dos programas encontrados sejam tão diferentes entre si, pois buscam suprir as carências das empresas participantes e atender as expectativas de suas âncoras. Essas por sua vez possuem problemas e necessidades semelhantes por serem empresas de grande porte e atenderem a certificações internacionais além de exigências de seus próprios clientes quanto a sua cadeia de fornecedores. 
A partir desse ponto, é sugerido para as futuras pesquisas que haja amplificação das análises aqui apresentadas através de uma comparação de resultados obtidos entre as empresas que passaram pelo programa e como foi seu desenvolvimento após o programa.

\section{REFERÊNCIAS}

BITTAR, H. C. J. Informações sobre o Programa de Qualificações de Fornecedores MS. [mensagem pessoal] Mensagem recebida por: < daianabonafe@ hotmail.com >. em: 25 jan. 2017.

BOSI, G. de L. C. Informações sobre o Programa de Qualificações de Fornecedores PE. [mensagem pessoal] Mensagem recebida por: < daianabonafe@ hotmail.com >. em: 27 jan. 2017.

CHING, H. Y. Gestão de estoques na cadeia de logística integrada. São Paulo, Atlas. 1999.

DEMING, W. E. Qualidade: A Revolução da Administração. Rio de Janeiro: Marques Saraiva, 1990.

FERREIRA, J. J. do A. Modelos Normatizados de Sistema de Gestão. Conceitos e Certificação: ISO 9001; ISO 14001 e TS 16949 in Gestão da Qualidade: teorias e casos - Rio de Janeiro: Elsevier, 2005.

FONSECA, J. J. S. da. Metodologia da pesquisa científica. Fortaleza: Uec, p. 65-75, 2002.

GERDAU (Brasil). Programa de Desenvolvimento de Fornecedores da Gerdau capacita mais de 400 empresas. Disponível em: <https://www.gerdau.com/br/pt/media-center/noticias/programa-dedesenvolvimento-de-fornecedores-da-gerdau-capacita-mais-de-400-empresas >. Acesso em: 25 jan. 2017.

HAHN, C. K.; WATTS, C. A.; KIM, K. Y. The Supplier Development Program: A Conceptual Model. A Journal of Purchasing and Materials Management; Spring 1990, 26,2; ABI/INFORM Global pg. 2.

IEL-PE. Qualificação de Fornecedores: competitividade local. 2017. Elaborada por IEL/PE. Disponível em: < http://www.ielpe.org.br/qualificacaoFornecedores/setorAutomotivo.php >. Acesso em: 23 jan. 2017.

KOTLER, P. Administração de Marketing. 10.ed. São Paulo: Prentice Hall, 2000.

KRAUSE, D.R.; ELLRAM, L.M. Success factors in supplier development. International Journal of Physical Distribution \& Logistics Management. Vol. 27, No.1,1997, pp. 39-52.

MAIA, J. L.; CERRA, A. L. Relacionamento entre empresas na cadeia de uma montadora de motores: uma análise a partir da Economia de Custos de Transação. In: SIMPEP-Simpósio De Engenharia De Produção. 11. 2004. Anais... Bauru/SP, 2004 a. Disponível em: 〈 http://www.simpep.feb.unesp.br $>$

MCHUG, M.; HUMPREYS, P.; MCIVOR, R. Buyer-Supplier relationship and organizational hearth. The Journal of Supply Chain Management, p 15-25, May, 2003.

MOURA, L. R. Gestão do relacionamento com fornecedores: análise da eficácia de programa para desenvolvimento e qualificação de fornecedores para grandes empresas. 2009. 335 f. Tese (Doutorado) Curso de Engenharia de Produção, USP, São Paulo, 2009. Cap. 5. Disponível em: <

http://www.teses.usp.br/teses/disponiveis/3/3136/tde-01092009-153815/pt-br.php >. Acesso em: 16 dez. 2016.

NATURA (Brasil) (Ed.). Gestão de Performance e Relacionamento com Fornecedores: Qlicar. 2016. Disponível em: < http://www.natura.com.br/sites/default/files/static/fornecedores/qlicar.htm >. Acesso em: 18 dez. 2016. 
PEREIRA, D. C.; CARRARO, N. C.; SOUSA, M. A. B. de. Análise dos Resultados do Programa de Desenvolvimento e Qualificação de Fornecedores em Três Lagoas - MS. Revista Eletrônica Multidisciplinar Facear, Araucária, v. 3, n. 5, p.1-13, dez. 2016. Quadrimestral. Disponível em: < http://www.revista.facear.edu.br/artigo/\$/analise-dos-resultados-do-programa-de-desenvolvimento-equalificacao-de-fornecedores-em-tres-lagoas-ms >. Acesso em: 27 dez. 2016.

PQF, Revista (Brasil). BG2M (Ed.). Recertificar para se manter no mercado. Revista PQF: A Marca Da Qualificação, Três Lagoas, v. 01, p.34-37, abr. 2015. Trimestral.

PORTAL DA INDÚSTRIA (Brasil). CNI (Ed.). Programa de Qualificação de Fornecedores: Como funciona?. 2016. Disponível em: http://www.portaldaindustria.com.br/iel/iniciativas/programas/programade-qualificacao-de-fornecedores/2012/03/1,1892/como-funciona.html >. Acesso em: 16 dez. 2016.

RAUPP, F. M. (2009). BEUREN, I. M. Caracterização da Pesquisa em Contabilidade. In. BEUREN, Ilse Maria (Org). Como elaborar trabalhos monográficos em contabilidade: teoria e prática, v. 3.

SANTOS, A. R. dos. Informações sobre o Programa de Qualificações de Fornecedores. [mensagem pessoal] Mensagem recebida por: < daianabonafe@ hotmail.com >. em: 24 jan. 2017.

SEDIYAMA, R. S. Programa de Desenvolvimento de Fornecedores e Indução de Comportamentos de Melhoria Contínua: Estudo de Caso da Natura Cosméticos. 2012. 127 f. Dissertação (Mestrado) Curso de Administração de Empresas, Fundação Getúlio Vargas, São Paulo, 2012. Disponível em: < http://bibliotecadigital.fgv.br/dspace/bitstream/handle/10438/10335/Roberto\%20Seiti\%20Sediyama\%20\%20Disserta\%C3\%A7\%C3\%A3o\%20Vers\%C3\%A30\%20Final\%20\%20271212.pdf?sequence=1\&isAllowed=y >. Acesso em: 23 jan. 2017.

SILVEIRA, T. Programa de Desenvolvimento de Fornecedores Gerdau: identificando o perfil de novos participantes através dos Valores Pessoais de Rokeach. 2007. 89 f. TCC (Graduação) - Curso de Administração, Departamento de Ciências Administrativas (dca), Universidade Federal do Rio Grande do Sul, Porto Alegre, 2007. Disponível em: < http://www.lume.ufrgs.br/handle/10183/21547 >. Acesso em: 11 nov. 2016.

TRINDADE, E. (Espírito Santo). IEL NR ES (Ed.). Prodfor encerra o ano com evento de certificação. 2016.Disponível em: < http://www.iel-es.org.br/noticia/prodfor-encerra-o-ano-com-eventode-certificacao >. Acesso em: 17 dez. 2016.

VIEIRA, P. E. M. (Org.). Fibria apresenta cases sobre qualificação de fornecedores e sustentabilidade na $6^{\text {a }}$ Feira do Empreendedor. 2014. Elaborado por Jornal do Dia. Disponível em: < http://tissueonline.com.br/fibria-apresenta-cases-sobre-qualificacao-de-fornecedores-e-sustentabilidadena-6a-feira-empreendedor/ >. Acesso em: 09 set. 2016. 